\title{
An International Comparative Study of Environmental Taxes
}

\author{
Huayong $\mathrm{Niu}^{1, \mathrm{a}^{*}}$, Shipeng Xie $\mathrm{X}^{1, \mathrm{~b}}$ \\ ${ }^{1}$ International Business School of Beijing Foreign Studies University, Beijing, China \\ aniuhuayong@bfsu.edu.cn, ${ }^{\mathrm{b} x i e s h i p e n g @ b f s u . e d u . c n}$ \\ ${ }^{*}$ Corresponding author
}

\begin{abstract}
. with the increasingly growing environmental crisis represented by haze in recent years, China is bearing more and more pressure on reducing fossil energy consumption and emission of greenhouse gas. The reform on green tax system represented by environmental taxes is not only imperative to speed up the transformation of economic development patterns and realize energy safety and resource conservation, but also an important way to cope with the challenge of global climate change and moreover a direct demand on reducing environmental pollution to improve the livelihood of people. By comparing the implementation status of environment tax in 19 major countries and regions of the world, this paper summarized the common practice on the implementation of environmental taxes, analyzed the regularity and loophole, and proposed for some suggestions on implementation of environmental taxes in China.
\end{abstract}

Keywords: Environmental taxes, Object of taxation, Taxation basis.

\author{
环境税的国际比较研究 \\ 牛华勇 ${ }^{1, \mathrm{a}^{*}}$, 谢士鹏 ${ }^{1, \mathrm{~b}}$ \\ 1 北京外国语大学国际商学院, 北京, 中国 \\ aniuhuayong@bfsu.edu.cn, ${ }^{b}$ xieshipeng@bfsu.edu.cn \\ *通讯作者
}

中文摘要. 近年来, 以雾霧等为代表的资源 环境危机因素日益凸显，中国在改善环境、 减少化石能源消耗、降低温室气体排放等方 面的压力愈来愈大。以环境税为代表的绿色 财税制度改革, 是加快经济发展方式转变, 实现能源安全和资源节约的客观要求, 也是 应对全球气候变化挑战的重要方式, 更是减 少环境污染改善民生的直接要求。本文通过 对比十九个世界重要国家和地区的环境税 实施状况, 总结了环境税实施过程中的通行 做法, 探讨和分析了其中的规律和漏洞, 并 为中国环境税的研究和实施提出了建议。
关键词：环保税；课税对象；计税依据

\section{1. 引言}

近些年来, 随着我国经济的快速增长, 环境污染和资源破坏问题也日益凸显，业已 关系到我国经济社会的长期可持续发展。在 市场需求的驱使下, 生产者往往只关注本部 门利益而扩大生产, 却往往忽略了生产过程 本身可能带来的环境污染和资源破坏问题, 或者没有为其承担充分的成本和责任。环境 污染和资源破坏本质上是一种经济问题, 也 
应该通过经济的手段去解决, 而税收作为一 种政府调节经济的手段也应被加以利用。税 收在环境资源领域则相应地体现为环境税。 本文旨探讨和分析世界主要国家的环境税 实施状况, 总结环境税在实际实施中的一般 规律和通行做法, 为我国环境税政策的研究 和实施提供借鉴和建议。

\section{2. 环境税实施背景和相关理论}

环境税是为应对人类社会日益严重的 环境污染和资源破坏问题而产生的, 并随着 20 世纪90年代以来人们对可持续发展日益 形成共识的基础上被各国所广泛接受和实 施的政策手段。环境税并不是一个单一的税 收项目, 而是一个多方位的全面的税收体 系。它一方面包括对实际排放的污染物征收 的税收, 另一方面包括对于环境资源开发利 用行为或生产的特定产品所征收的税收。

\section{1 外部性理论}

经济的外部性是经济主体 (包括厂商或 个人) 的经济活动对他人和社会造成的非市 场化的影响。即经济主体从事经济活动时产 生的成本与后果不完全由该行为人承担。外 部性分为正外部性和负外部性。负外部性是 某个经济行为个体的活动使他人或社会受 损, 却没有为此承担责任和成本。环境税主 要面向经济活动的负外部性。

\section{2 庇古税理论}

导致市场配置资源作用失效的原因是经济 主体的私人成本与社会成本不一致, 从而私 人的最优导致社会的非最优。纠正负外部性 的方案是政府通过征税来矫正经济主体的 私人成本, 使得私人成本和私人利益与相应 的社会成本和社会利益相等。这种纠正外部 性的方法也称为 “庇古税” 方案。通过征收 环境税, 可以让经济主体为自己的行为承担 责任和损失, 将污染的成本内化到经济主体 的生产活动中。

\section{3 双重红利理论}

环境税可以带来 “双重红利”，即 环境税的开征不仅能够有效抑制污染, 改善 生态环境质量, 达到保护环境的目标, 而且 可以利用其税收收入降低现存税制对资本、
劳动产生的扭曲作用, 从而有利于社会就 业、经济持续增长等, 即实现 “绿色红利” 和 “蓝色红利”。

\subsection{1 绿色红利}

直观来看, 通过征收环境税, 可以增加 经济主体的生产成本, 减少其生产量, 从而 减少其资源消耗与污染排放量, 起到改善生 态环境的作用。这是环境税的绿色红利。

\subsection{2 蓝色红利}

从长期来看, 排放主体为了提高经济效 益, 会不断地改进生产技术和设备, 实现节 能减排和提高经济效率。同时，政府可以通 过适当的税收征收和支出结构的调整有效 避免资源破坏、环境污染的不利影响, 并对 经济发展、改善经济结构、增加就业等产生 促进作用。另外, 在税收的支出方面, 政府 可以将环境税税收收入作为专项资金, 用于 环保技术和设备的研发, 支持低能耗低污染 产业和企业的发展和环保活动, 获得经济发 展和环境保护的双重效益。

\section{3. 世界主要国家环境税对比分析}

世界各国的环境税的设定和具体征收做 法差别较大, 但也呈现了一些一般的特征。 在税收基本要素、税收分配和使用、税收优 惠等方面有许多相同或相通之处。

\section{1 税收分类}

虽然各国的环境税具体名称、科目等差 别较多, 但总体上可以分为五类, 即能源税、 资源使用税、交通税、污染物排放税和特定 行为税。也有个别国家将环境嵌入到消费 税、所得税中去, 通过其他税收形式一并征 收。

表1. 环境税种分类

\begin{tabular}{|c|c|c|c|c|c|}
\hline $\begin{array}{l}\text { 税 } \\
\text { 种 }\end{array}$ & $\begin{array}{c}\text { 能源 } \\
\text { 税 }\end{array}$ & $\begin{array}{c}\text { 资源使用 } \\
\text { 税 }\end{array}$ & 交通税 & $\begin{array}{c}\text { 污染物排 } \\
\text { 放税 }\end{array}$ & $\begin{array}{c}\text { 特定行 } \\
\text { 为税 }\end{array}$ \\
\hline $\begin{array}{l}\text { 征 } \\
\text { 税 } \\
\text { 范 } \\
\text { 围 }\end{array}$ & $\begin{array}{l}\text { 化石 } \\
\text { 能源 } \\
\text { 电能 }\end{array}$ & $\begin{array}{l}\text { 矿产资源 } \\
\text { 土地资源 } \\
\text { 水资源 } \\
\text { 渔猎资源 } \\
\text { 生物资源 }\end{array}$ & $\begin{array}{c}\text { 机动车税 } \\
\text { 车辆购置、 } \\
\text { 注册和牌照 } \\
\text { 获取 } \\
\text { 道路相关税 } \\
\text { 收 }\end{array}$ & $\begin{array}{c}\text { 空气污染 } \\
\text { 物 } \\
\text { 温室气体 } \\
\text { 固体废弃 } \\
\text { 物 } \\
\text { 各类垃圾 } \\
\text { 处理 }\end{array}$ & $\begin{array}{c}\text { 车船保 } \\
\text { 有 } \\
\text { 航行 } \\
\text { 飞行 } \\
\text { 包装 } \\
\text { 开采权 } \\
\text { 持有 } \\
\text { 工程承 } \\
\text { 包 }\end{array}$ \\
\hline
\end{tabular}


能源税和资源使用税本质上都是直接对 自然资源的开发和使用数额进行征税, 因为 能源消耗量巨大且占自然资源消费消耗总 量比重较大,故将其单独作为一个类别。

针对能源和资源使用直接征税优点如 下: 第一, 针对性强, 可以直接限制能源和 资源的使用，从根本上防治环境资源问题。 第二, 直接面向资源能源, 便于与政府的其 他非环境目的的能源资源政策相配合和协 调。第三, 便于监控和计量。能源和资源相 关的交易数量通常较大, 其开采、加工和销 售渠道较为明确和单一, 因而便于追踪、监 控、统一计量和税收征管。

针对能源和资源使用直接征税也有其缺 点和问题: 首先, 与最终环境目的有一定脱 节。环境问题是能源资源消耗带来的污染物 排放造成的。单纯提高企业在能源和资源方 面的成本并不能有效刺激企业进行环保和 治污方面的努力和投资, 单位产量的污染量 不会变。其次, 容易造成事实上的不公平。 能源和资源的使用目的各异, 某些特定用途 并不会带来严重的环境问题, 而统一的能源 和资源使用税会忽略这些问题。即使在环境 税具体征管中对各种用途进行区别, 难度和 障碍也会非常巨大。另外对于同一用途的资 源能源消耗, 不同企业的资源利用效率、排 污量和环境污染量也是不同的, 如果按统一 标准征收环境税会影响那些在节能环保方 面表现较好企业的积极性。

针对污染物排放征收的环境税与针对能 源资源使用征收的环境税优缺点恰恰相反。 针对污染物排放征税可以真正体现环境税 的环境目的, 可以促进企业减少排放, 改进 能源和资源利用效率以及单位能源能源消 耗。且可以充分考虑到能源资源的不同用途 以及不同企业的实际情况, 差别对待, 体现 环境税的公平性。但污染源通常数目众多, 分布零散且多隐蔽, 监控和计量起来较为困 难。且污染物排放监控设施相关的资金投入 量大, 还需要专门的保护和监督使用, 实际 操作起来困难重重。

交通税和特定行为税则是从企业或个人 的交通驾驶和其他可能带来环境问题的行 为出发, 其优缺点也可以从上述两种环境税 政策的分析中看出。

\section{2. 课税对象}

课税对象是环境税征收直接面向的主 体, 总体来看各国环境税的课税对象主要分 四类:危害环境的产品、排放的各类污染物、 各类稀缺自然资源以及特定的生产或消费 行为。

危害环境的产品包括密集使用化石能 源、矿产资源生产的产品、化学产品等。各 类污染物包括氮、硫、二氧化碳等各类有毒 或温室气体, 污水等各类液体污染物, 以及 各类堆积物和固体污染物。稀缺资源则包括 各类矿产资源、化石能源、土地、森林、生 物等自然资源。而需交纳环境税的特定行为 则包括消费密集使用各类稀缺资源生产的 产品或会造成环境污染的产品、保有车船飞 行器等交通工具、使用各种材料进行包装以 及驾驶机动车、飞行、航行等特定的行为。 这四种课税对象实则涵盖了从自然资料开 发利用到生产再最后消费的整个过程, 保证 了能够全面对污染环境和破坏资源的行为 进行全面限制，达到环境税制定的目的。

\section{3 计税依据}

各国在环境税征收上主要采用从量计税 和从价计税两种方式。从量计税的方式主要 面向大宗的能源、资源使用行为、车船飞机 等大型的交通工具、各类大型机器设备或适 宜按单件进行统计和征收税收的实体。在对 能源使用征收环境税上又包括按照能源使 用量和能源使用实际产生的能量或排污量 计税两种方式。从量计税只需要计算能源或 各类设施的重量即可, 操作起来较为简单可 行, 但容易造成一定的税负不公平。从量计 税忽略了每一课税对象的实际资源消费和 环境污染量, 按照统一的税负分配方式计 税, 影响了部分在节能环保方面落实效果较 好的主体的积极性。按照资源能源使用造成 的实际污染量和资源破坏程度征税则较为 公平, 但实际操作上难度较大, 将面临一系 列的技术、监管等方面的难题。因而这也是 一个需要综合权衡的方面。

从价计税方式则适用于那些本身质量或 体积小、资源能源消耗量小, 却价值高且污 染严重的物品, 如农药、杀虫剂等化学产品。 从量计税和从价计税方式有各自的适用范 
围和对象, 应区别加以使用, 或者联合加以 利用, 以起到更好的环保效果。

\section{4 税收优惠}

环境税会增加企业生产、居民生活的成 本, 一定程度上影响经济发展。大多数国家 为了缓解环境税政策对公众生产生活成本 带来的突然影响, 以及避免对经济的过度干 扰, 会在环境税实施初期阶段给予特定部门 一定的税收减免或优惠措施。这些部门一般 为基础或公共经济部门和产业, 如公共交 通, 农业, 出口部门, 清洁能源和环保部门 以及使用清洁能源和在节能环保方面表现 突出的个体, 企业和部门。这些税收减免优 惠措施不仅是出于对特写部门的保护, 还可 以作为奖励措施加以推广以起到激励各企 业或部门进行节能减排努力的效果。

\section{5 税收归属}

大多数国家在环境税上采取了中央税和 地方税相结合的办法, 中央政府和地方政府 分别征收特定环境税种, 或在特定税种收入 上进行共享。有些国家的地方政府在环境税 立法和具体征收方面具较高的自主性和灵 活性, 或由地方的试点和倡导进而向全国范 围推广。环境税与中短期内的经济发展有一 定的冲突, 给予地方政府一定的自主权, 既 有利于调动地方政府配合环境税实施的积 极性, 又可以从各地不同的实际情况出发, 使环境税和经济社会发展相协调。

\section{6 环境税税收用途}

环境税和其他税收收入一样, 是国家财 政收入的重要组成部分, 可以用于支持国家 的财政支出。但环境税为防治污染和保护环 境资源而设立的初衷, 加之其经济影响的范 围之广, 都决定了环境税收并不能完全像其 他税收那样用于一般的财政收支目的。环境 税收的使用有其特殊性。很多国家为资源环 境保护的目的而设立环境税, 然后将所得的 税收收入再用于资源环境保护的努力, 如用 于污染治理, 支持生产设施的环保改造升 级, 公共绿化, 或用于成立专项的基金以支 持资源环境保护工程项目, 相关技术的开 发, 利用和培训。

\section{7 环境税征收面向的部门}

企业和居民是税收征收面向的两个主 体。企业的生产活动和居民的生活和消费活 动都会造成资源能源的消耗和环境污染, 因 而理论上讲对这两个主体都应该征收环境 税。但考虑到征收的难度和对消费者个人利 益的保护, 多数国家主要面向企业征收环境 税, 对个人或家庭征收的环境税主要体现在 汽车或特定物品的保有和消费方面。只有少 数国家面向居民或家庭的住房和能源消费 等方面征收环境税。但由于企业往往可以将 环境税所造成的生产成本增加通过产品价 格转移到消费者身上，因而个人消费者往往 又成为环境税的最终承担者, 这样未必能起 到限制企业排放和污染的目的。因而可考虑 以直接税的形式向企业征收环境税，防止企 业将成本转嫁。

\section{8 各国环境税制的实施情况}

从目前各国的环境税制实施情况来看, 国际环境税主要呈现出以下特点:

环境税涵盖范围广泛。多数国家实行了 针对能源消费、高能耗高污染产品生产到交 通工具使用、污染物排放、特定环境污染后 果全面征收环境税的政策。征税范围涵盖了 各类能源、化学品、交通工具以及各类有害 物质排放和垃圾生产活动。许多国家制定了 极为精细的环境税目录, 囊括了各类破坏资 源环境的物品和行为, 全面控制资源消耗和 环境破坏。

以能源税为主体。能源消费是大多数国 家资源环境问题的主要诱因, 因而针对能源 使用征收的税收也成为环境税的主要内容。 大多数国家都有针对各类能源使用和生产 设施征收的环境税科目。

基本而言, 各国都是根据本国特定的环 境问题、经济结构、财税状况实际而确定的 环境税科目和税率, 且在本国内实施的时候 也具有较强的灵活性, 如给予地方政府较多 的税收自主权, 差别税率对待, 税收优惠等。

\section{4. 世界主要国家环境税政策对我国的启示}

从我国环境和资源问题的实际情况和经 济社会发展和转型的需要出发, 认清具体的 需要治理的环境问题和需要保护的资源种 
类, 在此基础之上制定明确详细的环境税科 目和细则。但资源环境保护是一个长期的问 题, 环境税一旦实施也将给企业和居民带来 一定的冲击, 因此环境税的实施应循序渐 进, 不断深入和细化, 征税范围由窄到宽, 税率由低到高, 避免环境税实施对经济的过 度干扰。在环境税具体类别的选择上应综合 考虑环境目的、政策的可协调性、技术和操 作难度、实际投入、税收的公平性等方面的 因素。

确定合理的税收征收环节和计税方式。 环境资源问题产生的过程为资源开采一产 品生产一消费一污染物排放等环节。每一特 定的资源环境问题产生在这一链条的不同 环节之上, 在征税之时应明确问题产生或最 突出的环节。计税方式主要有从量计税和从 价计税两形式。对于那些数量和污染量都较 为庞大的物品适宜采取从量计税的方式, 而 对于那些数量少、价值高的物品则适合从价 计税的方式。此外, 征税中应考虑基于资源 能源使用量还是污染排放量。基于资源能源 使用量更加方便计量和征收, 但会忽略其实 际环境破坏结果, 产生事实上的不公平。而 基于污染排放量征税较为公平, 但又存在监 控、计量方面的难题。因此这两方面的权衡 和选择也是环境税征收应该考虑的一个问 题。

注重环境税的针对性和灵活性, 扩大地 方政府自主性。环境税牵涉的经济部门和地 域范围较广, 由于各地区在资源环境问题和 经济发展上差别较大, 各经济部门的受影响 程度也不尽相同。在具体的环境税制定和征 管上应充分考虑各地区各部门的差别, 采用 灵活的税率和税收优惠措施, 对落后地区、 公共经济部门和消费者等给予特定的保护。 给予地方政府在环境税政策方面一定的自 主性, 使其在资源环境保护上能够权责相 符, 从而提高其积极性和主动性。

注意环境税与传统税费政策的协调。我 国已有的某些税费科目反映了环境保护方 面的诉求, 如要征收统一的环境税, 则应做
好与现在税费政策的协调, 防止对企业或个 人重复征税，增加其负担。

\section{5. 结束语}

我国目前缺少针对环境污染资源破坏征 收的专门性税种, 即真正意义上的环境保护 税, 且已有的与环境相关的税费针对性不 强, 细则不够具体, 且对于环境的保护作用 效果不够明显。实现全面系统的环境税政策 是我国下一步应逐渐采用的政策选择。全面 了解国际环境税实施细则和通行做法, 对我 国环境税政策的制定和开征具有较强的借 鉴意义。

\section{致谢}

本文为北京外国语大学规划项目《发达 国家对二氧化碳排放的税收制度研究》 （2011XG003）的阶段性成果之一。

\section{References}

[1] Chen Shaoqiang, Cai Xiaoyan, The reflections of Environmental Tax in Developed Countries to China. China Development Observation, 2008(5): 58-60.

[2] He Yunjing Huang Delin, Lu Hongguang, Xu Yanru, Xie Chang, A Study of China's Environmental Tax Mode Selection. Land and Resources Economy of China, 2013 (7) : 47-52.

[3] Liao Qingzhen, Environmental Tax of China: International Experience and System Conception. Anhui University of Finance, 2014.

[4] Shen Jianjun. The Theory of Environmental Tax and Its Application in China. Southwestern University of Finance and Economics, 2007.

[5] Wu Junpei, Li Miaomiao. The Environment of China in International perspectives. International Tax, 2011(8), 22-25.

[6] Xu Hong. A Study of Improving China's Environmental Tax by drawing experience of developed countries, Jilin University, 2014.

[7] You Zhijing. The International Comparision of Carbon Tax. Shanghai Academy of Social Science, 2012. 